УДК 31

DOI $10.21661 / \mathrm{r}-470420$

\title{
О.А. Ефанова
}

\section{ОСОБЕННОСТИ МОНИТОРИНГА МЕРОПРИЯТИЙ ГОСУДАРСТВЕННЫХ ЦЕЛЕВЫХ ПРОГРАММ И ПРОЕКТОВ}

Аннотация: в статье рассматривается специфика мониторинга мероприятий государственных ијелевых программ и проектов как управленческого инструмента. Выявляется его отличие от оченки их качества, подчеркивается роль и необходимость измерения отношения целевой аудитории к проведенным мероприятиям.

Ключевые слова: мониторинг, челевая программа, эффективность, оценка, показатели.

\section{O.A. Efanova}

\section{FEATURES OF STATE TARGET PROGRAMS AND PROJECTS MONITORING}

Abstract: specifics of actions on state target programs and projects monitoring as managerial tool are considered in article. Its difference from assessment of their quality comes to light, the role and the need of relation measurement of target audience to the held events is emphasized.

Keywords: monitoring, target program, efficiency, assessment, indicators.

Повышение качества управления непосредственно связано с повышением эффективности реализации принимаемых программ и проектов. Понятие программы является основным понятием программно-целевого метода управления, который заключается в управлении социальным и экономическим развитием страны с помощью разработки и реализации специфических плановых документов - государственных целевых программ. В настоящее время это наиболее эффективный метод государственного управления.

Программы различаются по своей масштабности и подразделяются на федеральные, региональные, местные и ведомственные программы. Федеральные 
целевые программы реализуются на территории Российской Федерации, региональные - направлены на развитие конкретного экономического региона, местные (муниципальные) целевые программы - на развитие конкретного муниципального образования. На уровне министерств и ведомств принимаются ведомственные целевые программы.

Программы ориентированы на полное или частичное решение конкретной социально-экономической проблемы. Каждая конкретная программа включает цель, задачи, описание услуг, предоставляемых в рамках программы, потребителей этих услуг, перечень мероприятий, необходимых для достижения результатов программы в соответствии с поставленными целью и задачами, перечень плановых показателей реализации программы.

Программно-целевой метод подразумевает не только разработку, принятие, реализацию программ, но существенное внимание уделяется также мониторингу различных целевых программ с точки зрения оценки их эффективности.

«Мониторинг программы - это процесс регулярного измерения и учета важнейших индикаторов деятельности в рамках программы и ее результатов. Задачей проведения мониторинга программы является своевременное получение качественной (объективной, достоверной и полной) информации о ходе реализации программы» [2, с. 19].

Мониторинг программы направлен, в частности, на выявление следующих моментов: соблюдение плана реализации программы, то есть соответствие выполнения мероприятий программы определенному графику, степень достижения итоговых (промежуточных) результатов программы; число клиентов (благополучателей, бенефициаров), охваченных программой; эффективность программы.

Организация мониторинга программ и проектов имеет смысл только в случае его регулярного проведения и использования результатов мониторинга в управленческой практике. Мониторинг предоставляет возможность вовремя выявить недостатки программ и проектов, в том числе определить недостаточность или, напротив, излишество финансовых ресурсов для реализации программ и проектов. 
В эффективной работе программы заинтересованы разные стороны, как органы управления, так и целевая аудитория, на которую направлена программа. В этой связи обеспечение обратной связи от бенефициаров об их удовлетворенности предоставляемыми услугами в рамках программы или от экспертного сообщества об эффективности реализации программы во многом стимулируют органы управления к повышению качества и результативности их работы.

Мониторинг программ и проектов следует отличать от еще одного управленческого инструмента, используемого для экспертизы качества программ и проектов - их оценки. Эти два метода очень близки, однако в первую очередь именно регулярность проведения мониторинга отличает его от оценки программ и проектов, которая проводится по мере необходимости. Мониторинг предваряет оценку, являясь основанием для ее проведения. При этом оценка не ограничивается только данными мониторинга. В ходе оценки выполняется более глубокий анализ информации о программе.

Мониторинг и оценка являются взаимодополняющими инструментами получения новой информации о функционировании программы, но заменить друг друга они не могут.

«Мониторинг - это процесс текущего измерения и учета важнейших индикаторов деятельности по программе и ее результатов. Оценка - это экспертиза программ и проектов, направленная на анализ их качества, произведенного ими эффекта и сравнение полученных результатов с определенными критериями» [3, c. 156].

Как правило, основа методического инструментария мониторинга программ включает следующие виды оценки:

1. Оценка эффективности разработки программы.

2. Оценка эффективности реализации программы.

3. Оценка эффективности управления реализацией программы.

Целевые программы, в основном оцениваются по следующим признакам:

- соответствие программ интересам населения;

- уровень проработки целевых показателей (индикаторов); 
- уровень результативности целевых программ;

- степень финансовой обеспеченности бюджета программы;

- ход выполнения мероприятий реализуемых программ;

- динамика показателей экономической и социальной эффективности реализации целевой программы.

Существуют и реализуются комплексные подходы к мониторингу программ и проектов. При таком подходе применяется оценка, как эффективности, так и результативности программ и проектов. В этой связи необходимо различать эффективность расходов на реализацию конкретных мероприятий и эффективность расходов на реализацию целевой программы.

Следует также различать понятия результативности и эффективности программы. Результативность представляет собой абсолютный показатель непосредственных результатов управленческого труда, тогда как эффективность - это относительный показатель, который устанавливает связь полученных результатов с затратами и позволяет определить, насколько оправданы расходы на мероприятия программы.

Необходимо также отличать мониторинг программ от механического учета данных. В процессе мониторинга происходит тщательный отбор информации, способствующей выявлению и решению проблем. На это направлен весь механизм осуществления мониторинга, предполагающий последовательное прохождение ряда взаимосвязанных этапов.

На первом этапе определяются характеристики программы (проекта), наиболее значимые для оценки ее эффективности. Затем выделяются показатели оценки реализации программ (проектов), значение которых будет отслеживаться в ходе мониторинга. Важную роль играет выбор источников информации для осуществления мониторинга. Это могут быть статистические данные, данные социологических опросов, документы и др.

На следующем этапе определяются методы сбора информации, ее периодичность и график, избираются технологии обработки и анализа собираемой информации, назначаются кураторы и ответственные за сбор информации. Важное 
значение для успешного применения мониторинга в управленческой деятельности имеет четкое определение пользователей его данных, а также подготовленность управленческого персонала к продуктивному использованию результатов мониторинга.

Следует отметить, что неподготовленность управленцев в этой области создает значительную трудность в применении результатов мониторинга программ и проектов. Определенные сложности в проведение мониторинга вносят также сравнительно высокие финансовые затраты на его разработку, организацию и проведение. В связи с этим расходы на проведение мониторинга должны учитываться в бюджете программы на стадии ее проектирования.

Важное значение для успешной реализации мониторинга программ и проектов и применения его результатов имеет качественная проработка каждого из его этапов. Недооценка какого-либо из них способна оказать негативное воздействие на достижение целей мониторинга и привести к существенному снижению достоверности и полноты информации.

Степень достижения результатов программы определяется на основании значений плановых количественных и качественных показателей (индикаторов), утвержденных на этапе разработки концептуальной части программы. Целевые индикаторы и показатели, позволяющие ежегодно отслеживать ожидаемую эффективность и результативность программы, составляют специальный раздел программы.

Количественные показатели определяют меру или степень выраженности определенных характеристик и процессов, качественные - фиксируют преобразования качественного характера. Фактические значения индикаторов определяются в процессе мониторинга.

Так, например, в Государственной программе «Патриотическое воспитание граждан Российской Федерации на 2016-2020 годы» предусмотрены следующие плановые показатели: 
Количество подготовленных организаторов и специалистов в сфере патриотического воспитания, в том числе специалистов военно-патриотических клубов и объединений (к 2020 г. - 55000 чел.).

Доля обучающихся в образовательных организациях всех типов, принимавших участие в конкурсных мероприятиях, направленных на повышение уровня знаний истории и культуры России, своего города, региона, в общей численности обучающихся (к 2020 г. - 180\%).

Доля участвующих в реализации Программы образовательных организаций всех типов в общей численности образовательных организаций (к 2020 г. - 150\%).

Доля общеобразовательных, профессиональных и образовательных организаций высшего образования, над которыми шефствуют воинские части (корабли) (к 2020 г. - 150\%).

Доля воинских частей (кораблей), над которыми шефствуют трудовые коллективы, бизнес-структуры, районы, города, области, края и республики (к 2020 г. - 150\%).

Доля информированных о мероприятиях Программы граждан Российской Федерации в общей численности граждан Российской Федерации (к 2020 г. - 300\%).

Доля субъектов Российской Федерации, в которых принята программа субъекта Российской Федерации в сфере патриотического воспитания, в общей численности субъектов Российской Федерации (к 2020 г. - 100\%).

Количество субъектов Российской Федерации, в которых создан региональный центр патриотического воспитания (к 2020 г. - 85 единиц) [1].

Зачастую эффективность некоторых программ недостаточно оценить только формальными показателями. Так, рассматривая плановые показатели Государственной программы «Патриотическое воспитание граждан Российской Федерации на 2016-2020 годы», следует отметить, что перечисленные количественные показатели не позволяют в полной мере оценить, имеет ли реализация программы положительный эффект. Только на основании данных показателей 
провести подобную оценку невозможно. Основным результатом реализации Программы должно стать «формирование системы патриотического воспитания граждан, отвечающей современным вызовам и задачам развития страны, а также социально-возрастной структуре российского общества» [1].

В этой связи важным инструментом измерения эффекта от внедрения программ является измерение отношения к программам, проектам и их последствиям среди заинтересованных лиц, то есть среди граждан Российской Федерации или конкретных групп населения. Таким путем, с помощью изучения оценок, мнений и суждений граждан, можно определить положительные сдвиги общественного восприятия каких-либо явлений действительности, проследить, например, динамику патриотических настроений населения, что позволит говорить о социальном эффекте от внедрения программы по патриотическому воспитанию граждан.

\section{Сиисок литературы}

1. Государственная программа «Патриотическое воспитание граждан Российской Федерации на 2016-2020 годы» [Электронный ресурс]. - Режим доступа:

http://government.ru/media/files/8qqYUwwzHUxzVkH1jsKAErrx2dE4q0ws.pdf (дата обращения: 15.11.2016).

2. Кодекс лучшей практики в сфере муниципального управления / Под ред. Г.Ю. Ветрова, Ю.С. Зайцевой. - М.: Фонд «Институт экономики города», 2004. -247 c.

3. Управление муниципальным экономическим развитием / Под ред. Г.Ю. Ветрова - М.: Фонд «Институт экономики города», 2009. - 372 с.

\section{References}

1. Gosudarstvennaia programma "Patrioticheskoe vospitanie grazhdan Rossiiskoi Federatsii na 2016-2020 gody". Retrieved from http://government.ru/media/files/8qqYUwwzHUxzVkH1jsKAErrx2dE4q0ws.pdf

2. Vetrova, G. Iu., \& Zaitsevoi, Iu. S. (2004). Kodeks luchshei praktiki v sfere munitsipal'nogo upravleniia., 247. M.: Fond "Institut ekonomiki goroda". 
3. Vetrova, G. Iu. (2009). Upravlenie munitsipal'nym ekonomicheskim razvitiem., 372. M.: Fond "Institut ekonomiki goroda".

Ефанова Ольга Алексеевна - канд. филос. наук, начальник отдела Российского студенческого центра ФГБОУ ВО «Московский авиационный институт (национальный исследовательский университет)», Россия, Москва.

Efanova Olga Alekseevna - candidate of philosophical sciences, the head of the department of the Russian student's center at the Moscow Aviation Institute (National Research University), Russia, Moscow. 